\title{
PLANNING A SUSTAINABLE TOURISM DESTINATION FOCUSING ON TOURISTS' EXPECTATIONS, PERCEPTIONS AND EXPERIENCES
}

\author{
Anna KYRIAKAKI* \\ University of the Aegean, Department of Tourism Economics and Management, Faculty \\ of Locality and Social Sustainability in Tourism, Chios, Greece, e-mail: a.kyriakaki@aegean.gr \\ Maria KLEINAKI \\ Hellenic Open University, School of Social Sciences, Patras, Greece, e-mail: mperson1245@gmail.com
}

\begin{abstract}
Citation: Kyriakaki, A., \& Kleinaki, M. (2022). PLANNING A SUSTAINABLE TOURISM DESTINATION FOCUSING ON TOURISTS' EXPECTATIONS, PERCEPTIONS AND EXPERIENCES. GeoJournal of Tourism and Geosites, 40(1), $225-231$. https://doi.org/10.30892/gtg.40127-823
\end{abstract}

\begin{abstract}
This study aims to research the special characteristics, expectations and experiences of the tourists a destination attracts and elaborate them during sustainable tourism planning in the effort to (re)build a destination. Research conducted in southern Chania, Crete, Greece based a) on a structured questionnaire to capture the characteristics of tourists visiting the area, their motivation and opinions b) a content analysis of the material posted on "Trip Advisor" in order to understand the perceived image of the area. Cluster analysis highlighted three groups a) the eternal lovers, b) the devoted families and c) the adventurers. All groups declared a high degree of satisfaction and loyalty to the destination and a strong interest in sustainable and alternative tourism. Nevertheless, the commercial image of the area continues to focus on the model "Sun - Sea - Sand", without sufficiently highlighting other local resources. The results can be the basis for the enrichment and upgrading of the quality of the existing tourism product, to be supported by a management model under the UN SDGs. This approach is expected to increase the competitiveness of the destination and lead to sustainable development.
\end{abstract}

Key words: Sustainability, alternative tourism, destination planning, tourists' clusters, Crete Greece

$* \quad * * * *$

\section{INTRODUCTION}

The profound change of the existing model of tourism development seems to be imperative for a number of small and medium-sized "Sun-Sea-Sand" Greek tourism destinations, which can be classified as "mature". These destinations have completed the successive stages of development-growth and entered a state of stagnation as shown by the stabilization in the growth rate of arrivals, the zero increase in beds, the reduced competitiveness, the almost homogeneous tourism product (Sarantakou, 2017). A new tourism development pattern based on quality, innovation and sustainability (López-Sánchez and Pulido-Fernández, 2016) with the enrichment of the tourism product (Prince and Ioannides, 2016) seems to be the best option for this type of destination in order to increase their attractiveness and competitiveness and ultimately reach the "rejuvenation" stage. During the last years, the concept of sustainability has been a hot topic for discussion in the tourism industry. Two facts highlighted its importance and accelerated the priority of its implementation: a) The issuance by the United Nations of the 2030 Agenda and the relevant, Sustainable Development Goals (SDGs), through which states, the public and the private sector are encouraged to plan and measure their contribution to sustainable development by $2030 \mathrm{~b}$ ) the pandemic of Covid-19, which has allowed the tourism industry to take a step back and assess the opportunity to improve its quality and become more thoughtful. Understanding of sustainable tourism has been limited almost exclusively to the supply perspective although tourist behaviour and attitudes play a key role when a mature destination aims to be reformed in a competitive and sustainable tourism destination (López-Sánchez and Pulido-Fernández, 2016). According to Kastenholz et al. (2018), visitors with sustainable behaviour play an important role in sustainable development promotion, not only during their visit but also in the long term, acting as positive word-of-mouth.

Based on the above argument, the study analyses the tourism demand of the south-western (SW) front of the Chania Regional Unit, Crete, Greece, a destination where tourism development began in the 70's and evolved in the coastal zone attracting a limited number of outbound tourist flows. The main aim of this article is to investigate the tourists' mindset, expectations and experiences and incorporate them into a sustainable tourism planning in the study area.

Research in the rural tourism market shows that particular tourist profiles, motivations and travel behaviours, imply more sustainable development opportunities than others, by promoting sustainability not only during the visit, but also in the long term by encouraging future visits not only by the visitor but also by others through positive word-of-mouth (Kastenholz et al., 2018). Sustainable travel behaviour is related to social interaction with local residents, nature and culture preservation, appreciating local products and activities, saving resources and recycling, engaging in nature and culture activities (Kastenholz et al., 2018). According to López-Sánchez and Pulido-Fernández (2016), assessing the

\footnotetext{
* Corresponding author
} 
meaning of sustainability from the tourist's perspective is a trending topic during sustainable development planning. Additionally, segmenting the tourism market and determining the characteristics of the clusters is crucial for a destination that aims to (re)position itself in the market as a sustainable tourism destination (Paulino et al., 2021). Furthermore, the motives of tourists, whether related to the attitudes, goals and needs that push them to travel (push factors) or to the characteristics that make a destination attractive (pull factors) are the main tools during the decision making process (Fraiz et al., 2020; Kyriakaki et al., 2019). Their study is increasingly important in understanding consumer behaviours as the motivations and needs of the tourists become more complicated, while at the same time the variety of options and tourism destinations is growing. Satisfaction from travel is also a compound concept that is mainly related to the emotional and perceptible values of the visitor. In any case, combined with the image of the destination, it is a crucial parameter for assessing the loyalty of the visitor to a destination and the intention to visit and to recommend it to acquaintances (Artuger and Çetinsöz, 2017; Carvache-Franco et al., 2020; Chiu et al., 2016; Kastenholz et al., 2018; Kyriakaki et al., 2017; Kyriakaki et al., 2016; Veasna et al., 2013). In addition, the destination image i.e. "the beliefs, ideas and impressions people have about a place or destination" (Artuger and Çetinsöz, 2017), is crucial in decision making. Tsartas et al. (2010) state that the differences between destinations consist in different ways in which someone imagines them. Given the explosive development of Information and Communication Technologies (ICT), the promotion of a place through digital visual and verbal content is the main tool of modern destination marketing. As stated by Cuenca et al. (2020), an adequate communication strategy can help in the construction of a particular brand identity. Assuming the importance of using visual content tools for the promotion of destinations, it is a matter of relevance for tourism organizations to know if the communication image is consistent with the information they want to convey.

According to Rate et al. (2018), tourism planning aims to take into account a number of factors related to the development of tourism (social, cultural, economic, physical, technical/technological, international relations, communication and infrastructure, administrative, legal and policy-making) as well as their future development to ensure that a destination remains attractive, providing the necessary guidance to increase its competitiveness and address its weaknesses. Therefore, tourism planning organizes the future of a tourism destination to achieve specific goals, acting as a guide for decision making. In particular, in the case of sustainable tourism development, planning has three main objectives (Ruhanen, 2010): a) maintain the value of local resources, b) provide a high quality experience to the tourists during the interaction with local resources, c) maximize the returned economic, social and environmental value in the host community.It is clear that the holistic approach of sustainable tourism development in relation to the environment, the society, the economy, requires a strategic approach with a generalized vision and a broader time frame in comparison to conventional tourism planning. Therefore, a participatory strategic planning is suggested that aims at developing a strong connection of both locals and tourists to the destination and its resources, better knowledge of how the tourism sector operates, strengthening of cooperation, mutual respect, and gaining environmental awareness. The complication of tourism destinations makes strategic planning a challenge due to the large number of the stakeholders involved. However, the prevailing approach to tourism planning is based on immediate profit, increasing volumes of tourists and facilities and ad-hoc treatment of opportunities and issues, simply providing short-term solutions to substantially long-term problems (Ruhanen, 2010; Soulard et al., 2018; Dolnicar, 2020; Rizal, 2020).

\section{MATERIALS AND METHODS}

The study area: The research area is the SW front of the Chania Regional Unit, Crete, Greece which administratively belongs to the municipality of Kantanos-Selino. It has strong locality elements due to its natural resources (most of them belong to Natura 2000 network), the unique ecological identity, the combination of gorges, mountains and sea landscape, the rich tangible and intangible cultural heritage and the authenticity of the local residents..The coastal zone is an area of moderate residential and tourism development around the settlements of Paleochora and Sougia. The mountainous hinterland includes many untouched small villages and settlements. The economy of the region is based on tourism but also on the primary sector. The tourism supply is characterized by small and medium size businesses which are concentrated almost exclusively in the coastal zone. The area, which is $70 \mathrm{~km}$ away from the main tourism city of Chania, has been developed as a destination with mixed development characteristics as mass tourism and alternative forms of tourism coexist in the area. According to the Hellenic Chamber of Hotels registry (personal communication, May 19, 2020), in 2019 the area had 20 hotels (all categories), 412 rooms and 806 beds. The area attracts a standard core of tourists as in 2018, 11,636 international and 2,269 domestic tourists visited the area which amounted to $1.2 \%$ of the inbound and $2.3 \%$ of the international and domestic tourism respectively visiting Chania Regional Unit (Hellenic Statistical Authority, 2019).

The research aims: The main aim of this study is to investigate tourist needs, expectations and experiences and involve them in a sustainable tourism planning of the area in order to rejuvenate the destination.

The research questions are as follows:

- Which types of tourists choose the area as a travel destination?

- How familiar and aware are the tourists with the concepts of mass tourism, alternative tourism and sustainability?

- What are the motivations of the tourists and how do they ultimately evaluate their experiences and their intention to revisit or recommend the destination?

- What is the current "destination image" and to what extent is it harmonized with the motivations and expectations of the tourists?

- How could the mindset, expectations and experiences of the tourists be utilized in order to transform the area into a sustainable destination? 
The Research Methods: Two surveys were conducted during the period August - October 2019. A primary quantitative research was conducted using a structured questionnaire. Convenience sampling was chosen as a nonprobability sampling technique of drawing data due to unavailability of resources. The sample was selected from a portion of the population (international tourists) because of its convenient accessibility and proximity to the researchers (Babbie, 2011; Christou, 1999). 350 questionnaires were distributed in co-operation with local hotels and 191 responses collected $(\mathrm{N}=191)$. The questionnaire contained 70 questions grouped in 8 sections. An initial draft of the questionnaire was piloted and improvements and corrections were made for the final version. Sociodemographic and travel characteristics of tourists at the survey area were assessed by 17 closed questions. Tourists' motivations, perceived experiences and opinions about local resources and attractions were captured by 45 closed-type questions, the majority of which were measured on a 5point Likert scale. A group of 5 open-ended questions targeted to the views of the respondents, in relation to the basic concepts of "mass tourism", "alternative tourism" and "sustainable development". Also, through a 10-point scale, an attempt was made to rate the current image of the area as an alternative tourism destination and an open-ended question asked respondents to cite European destinations where alternative forms of tourism were successfully developed.

Table 1. Profile of Tourist Clusters ( ${ }^{\mathrm{a}} 1$ : Never -5 : Very often)

\begin{tabular}{|c|c|c|c|c|}
\hline \multirow{2}{*}{\multicolumn{2}{|c|}{\begin{tabular}{|l|} 
Size of the cluster \\
\end{tabular}}} & Eternal Lovers & Devoted Families & Adventurers \\
\hline & & 0.36 & 0.34 & 0.30 \\
\hline Parameter & Categories & $\%$ & $\%$ & $\%$ \\
\hline \multirow{4}{*}{ Age } & $18-25$ & & 13.3 & 15.4 \\
\hline & $26-49$ & & 50.0 & 65.4 \\
\hline & $50-64$ & 64.5 & 30.0 & 19.2 \\
\hline & $65+$ & 35.5 & 6.7 & 0.0 \\
\hline \multirow{8}{*}{ Nationality } & German & 0.13 & 0.23 & 0.19 \\
\hline & Austrian & 0.13 & 0.03 & 0.35 \\
\hline & British & 0.26 & 0.07 & 0.08 \\
\hline & French & 0.06 & 0.20 & 0.08 \\
\hline & Italian & 0.00 & 0.17 & 0.04 \\
\hline & Other EU & 0.13 & 0.03 & 0.12 \\
\hline & Other non-EU & 0.10 & 0.13 & 0.04 \\
\hline & Unknown & 0.19 & 0.13 & 0.12 \\
\hline \multirow{3}{*}{ Marital Status } & Single & 38.7 & 6.7 & 26.9 \\
\hline & Couple & 58.1 & 3.3 & 69.2 \\
\hline & Couples with children & 3.2 & 83.3 & 3.8 \\
\hline \multirow{3}{*}{ Level of Education } & Primary & 6.5 & 13.3 & 19.2 \\
\hline & Secondary & 35.5 & 20.0 & 38.5 \\
\hline & Tertiary & 54.8 & 60.0 & 42.3 \\
\hline \multirow{4}{*}{ Employment Status } & Employee & 25.8 & 36.7 & 57.7 \\
\hline & Self-Employed & 29.0 & 43.3 & 19.2 \\
\hline & Retired & 38.7 & 3.3 & 3.8 \\
\hline & \begin{tabular}{|l|} 
Student \\
\end{tabular} & 0.0 & 10.0 & 15.4 \\
\hline \multirow{4}{*}{$\begin{array}{l}\text { Annual Household } \\
\text { Income }\end{array}$} & up to $20,000 €$ & 3.2 & 20.0 & 11.5 \\
\hline & $21,000-40,000 €$ & 32.3 & 23.3 & 30.8 \\
\hline & $41,000-65,000 €$ & 12.9 & 13.3 & 15.4 \\
\hline & $>65,000 €$ & 22.6 & 20.0 & 15.4 \\
\hline \multirow{5}{*}{ Whom you visit with } & Alone & 35.5 & 3.3 & 3.8 \\
\hline & Couple & 61.3 & 0.0 & 61.5 \\
\hline & Family & 0.0 & 80.0 & 0.0 \\
\hline & Friends & 0.0 & 0.0 & 34.6 \\
\hline & Family \&Friends & 3.2 & 16.7 & 0.0 \\
\hline \multirow{3}{*}{ Travel Booking } & Tour Operator & 16.1 & 6.7 & 0.0 \\
\hline & $\begin{array}{l}\text { On your own (Internet) } \\
\end{array}$ & 77.4 & 90.0 & 84.6 \\
\hline & Other & 3.2 & 3.3 & 15.4 \\
\hline \multirow{4}{*}{$\begin{array}{l}\text { Information Source } \\
\text { for Holidays Planning }\end{array}$} & Tour Operator ${ }^{\mathrm{a}}$ & (1.9) & $(1.7)$ & (1.5) \\
\hline & Friends \&Family $^{\mathrm{a}}$ & $(3.2)$ & (3.7) & $(3.8)$ \\
\hline & Internet \& Social Media ${ }^{a}$ & $(3.9)$ & $(4.3)$ & $(4.5)$ \\
\hline & Media (TV, Magazines) ${ }^{a}$ & $(2.2)$ & $(2.2)$ & $(2.2)$ \\
\hline \multirow{5}{*}{ Travel duration } & 2-4 days & 3.2 & 0.0 & 46.2 \\
\hline & 1 week & 25.8 & 36.7 & 34.6 \\
\hline & between 1 and 2 weeks & 6.5 & 3.3 & 7.7 \\
\hline & 2 weeks & 48.4 & 50.0 & 11.5 \\
\hline & $>2$ weeks & 16.1 & 10.0 & 0.0 \\
\hline \multirow{3}{*}{$\begin{array}{l}\text { Frequency of visits to } \\
\text { the area }\end{array}$} & $1^{\text {st }}$ time & 6.5 & 30.0 & 57.7 \\
\hline & $2^{\text {nd }}$ time & & 20.0 & 15.4 \\
\hline & more than 2 times & 93.5 & 50.0 & 26.9 \\
\hline \multirow{3}{*}{$\begin{array}{l}\text { Other areas of Crete } \\
\text { included in travel }\end{array}$} & No & 48.4 & 46.7 & 19.2 \\
\hline & Chania Regional Unit & 41.9 & 30.0 & 38.5 \\
\hline & Other areas of Crete & 6.5 & 20.0 & 34.6 \\
\hline
\end{tabular}

The last group included 3 single-answer multiple-choice questions in relation to the respondents' intentions to revisit the destination, recommend it to acquaintances and friends, and actively participate in a network to promote sustainable 
practices in the area. The Statistical Package for Social Sciences (SPSS, version 26.0) was used to analyse the data. The implemented statistics analysis were descriptive (numerical and graphical) and inferential (ANOVA test, Chi-square test- ${ }^{2}$ test, alpha level=.05). Cluster analysis and Factor analysis were also carried out to determine the tourists' clusters and to classify the tourism motivation and expectation, respectively. Methodology was based on the study of Carvache-Franco et al. (2020). The second survey included a content analysis of the photo posts and evaluations posted at 'Trip Advisor' by tourists having visited the survey area. The purpose was to comparatively evaluate the primary data in order to obtain a more integrated and documented opinion about the destination image as perceived by the tourists (Cuenca et al., 2020; Tsartas et al., 2010). A random sample representing the 50\% of the uploaded photos by the 26th June, 2020 was analyzed i.e. 3,897 photos for Paleochora and 642 photos for Sougia. The main themes of each photo post were classified into 8 categories in accordance with tourists' motivations. 'Trip advisor' reviews and ratings were also used to assess the popularity and quality of experience of local attractions and activities combined with relevant questionnaire responses.

\section{RESULTS AND DISCUSSION}

Cluster analysis of the respondents according to their sociodemographic and travel characteristics concluded that the variables "age", "travel group", "travel duration" and "frequency of visits" were stronger correlated (Table 1). Therefore, the following three clusters were identified:

The eternal lovers: They are comparatively the largest group (35.6\%). They are 50+ years old, have a high level of education, a middle annual household income and are mostly retired. They are devoted to the area as the vast majority has visited it more than 2 times. Their trip usually lasts two weeks or more and often includes other areas of Chania Regional Unit. They organize their own trip using the Internet and Social Media as a source of information to plan their holidays.

The devoted families: Equally important group (34.5\%). They are couples with children who belong to the age group 26-49 and travel as a family. They have a middle annual household income, a high level of education and are self-employed or employees. They like the area and the majority have visited it at least 2 times. Their journey usually lasts one to two weeks and often includes other areas of Crete. They almost always organize their own trip using the Internet and Social Media as a source of information to plan their holidays.

The adventurers: This group $(29.9 \%)$ concerns younger couples belonging to the age category 26-49. Most have a university or higher degree of education and a middle income while they are mainly employees. The majority visited the area for the first time and their trip lasts a maximum one week as it often includes other areas of Crete. They organize their trip almost exclusively on their own using the Internet and Social Media as a source of information to plan their holidays. All respondents have a clear view of the negative effects of mass tourism as opposed to the positive ones of sustainable development. Alternative tourism is viewed positively but its context seems unclear. The comparative figure is shown in Table 2.

Table 2. Standpoints about tourism models

\begin{tabular}{|c|c|c|}
\hline Mass Tourism & Alternative Tourism & Sustainable Development \\
\hline "low income/low behaviour" & "vacation for individuals" & $\begin{array}{c}\text { "good compromise between comfort, } \\
\text { nature and culture" }\end{array}$ \\
\hline $1 \%$ & & $3 \%$ \\
\hline \multicolumn{3}{|c|}{ Positive } \\
\hline
\end{tabular}

In relation to mass tourism, the answers of the respondents focus on a tourism model, which exceeds the carrying capacity of an area and leads to overcrowding mainly in the coastal areas with countless sunbeds, oversized all-inclusive hotels, noise, huge queues in front of tourism facilities or attractions, air and sea pollution, inability to relax, lack of authenticity, inability to explore an area and alienation of the local community because of tourism.

The model of alternative tourism is characterized as a "special way to travel - beyond the ordinary", which gives freedom and opportunities to explore hidden places and new ways of entertainment and enjoyment, while maintaining the idea of "minimal". The harmony between the tourism and local development and culture is emphasized, as well as the possibility to enjoy nature and experience the balance of tourism and the environment. Alternative forms of tourism activities include hiking, cycling, diving, safaris, yoga, agrotourism, ecotourism, acquaintance with local traditions and products, slow food. Concerns are expressed as to whether alternative tourism could introduce a new type of mass tourism.

Regarding the model of sustainable development, this is highlighted as a development strategy "for the good of us all". The respondents emphasized the concept of balance between society, economy and the environment, as well as the importance of reducing impact for the benefit of future generations. It is interesting that sustainable development is seen "as a good combination between comfort, environment and culture". The implementation of sustainability is considered important "for the preservation of the beauty of Crete", provided it includes the participation and support of the local 
community. Good practices proposed by respondents mainly relate to environmental protection such as reducing the use of plastics, waste treatment, use of renewable energy sources, reducing the volume of waste, recycling, organic farming and small-scale construction. It is worth noting that $53 \%$ of respondents are positive about their participation as volunteers in the development and implementation of sustainable practices in the region.

The above highlighted interests and opinions regarding tourism models, are also clearly represented in the respondents main motivations for visiting the destination, grouped to identify the prevailing trends and to correlate them with the results from clustering. As shown in Table 3, the unique 'Natural Environment' of the area in combination with the 'Sea \& Sun' experience and the opportunity for 'Relaxation \& Activities' are the key factors that motivate the respondents to travel and choose the specific destination. Moreover, they look for the 'Local authentic experience' in terms of culture, gastronomy and local products. The overall degree of satisfaction from the travel experience for all clusters is high (4.6 out of 5.0) and the close relationship between satisfaction, loyalty and recommendation is verified by the research data. The higher the level of satisfaction (for the study area) the more favourable the future behaviours- recommendation and intention to return. Tourists with 'very positive' travel experience, declared a $74 \%$ intention to revisit the area $\mathrm{x}^{2}(2, \mathrm{~N}=191)=10.74, \mathrm{p}<.05$ and a $72 \%$ willingness to recommend it as a holiday destination to their friends and family $\mathrm{x}^{2}(2, \mathrm{~N}=191)=12.47, \mathrm{p}<.05$.

Table 3. Motivation and Quality of Experience

\begin{tabular}{|c|c|c|c|c|c|}
\hline Main Motivation $^{\mathrm{a}}$ & Eternal Lovers & Devoted Families & Adventurers & Overall Expected $^{\mathrm{a}, \mathrm{c}}$ & Overall Perceived $^{\mathrm{b}}$ \\
\hline The local authentic experience & 2.9 & 3.5 & 3.1 & 3.2 & 4.1 \\
\hline Gastronomy & 3.8 & 4.1 & 3.8 & 3.9 & 4.5 \\
\hline Culture (Monuments \& Attractions) & 2.5 & 3.4 & 2.9 & 3.1 & 3.7 \\
\hline Culture (Local Traditions \& Events) & 2.4 & 3.2 & 2.6 & 2.9 & 3.7 \\
\hline Local Products & 3.0 & 3.3 & 2.9 & 3.2 & 4.3 \\
\hline Relaxation \&Activities & 3.9 & 3.9 & 3.6 & 3.8 & 4.4 \\
\hline Sports \& Activities & 2.4 & 2.7 & 2.8 & 2.7 & 3.9 \\
\hline Relaxation \& Tranquillity & 4.8 & 4.7 & 4.3 & 4.6 & 4.7 \\
\hline Local Hospitality & 4.6 & 4.3 & 3.7 & 4.2 & 4.7 \\
\hline Sea \& Sun & 4.1 & 4.0 & 3.9 & 4.0 & 4.4 \\
\hline Sea \& Sun & 4.9 & 4.8 & 4.9 & 4.9 & 4.8 \\
\hline Low Prices & 3.4 & 3.2 & 2.9 & 3.2 & 3.9 \\
\hline Natural Environment & 4.9 & 4.8 & 4.6 & 4.7 & 4.9 \\
\hline \multicolumn{4}{|c|}{$\begin{array}{l}\text { a } \text { 1: Not at all important }-5 \text { : Very important; }{ }^{b} 1: \text { Very Negative }-5 \text { : Very Positive } \\
\text { KMO Index }=0.556 \text { Bartlett's Sphericity test }(\chi 2=104.92, \mathrm{df}=45 \text {, Sig. } 0.000<0.05)\end{array}$} & 3.9 & 4.6 \\
\hline
\end{tabular}

Of particular interest is the observation that in most of the motivation factors examined, the perceived experience surpasses the expected one. These findings prove that the destination, except for the classic dominant product "Sea \& Sun", has additional competitive advantages, which the visitors discover during their travel and are related to locality elements and alternative forms of tourism (sports \& activities, local products, gastronomy, cultural resources). This research element is largely correlated with the monothematic "commercial" image promoted for the destination, as confirmed by additional research findings analysed below. The commercial image of the area has been accessed by analyzing thematically the photos included in the travel platform, 'Trip Advisor' and concern the two main tourism poles i.e. the cities of Paleochora and Sougia. The main themes of each photo were categorized in accordance with the motivations that lead the traveller to the area. The results are depicted in Table 4 . In the case of Paleochora, the image is dominated by the sea and the beach $(68 \%)$ while the settlement and lifestyle follow. Sougia's image is dominated by the relaxed lifestyle (35\%) in combination with the sea and the beach $(26 \%)$ and the natural landscape $(23 \%)$. It is noteworthy that in both destinations the themes related to culture, attractions, activities and gastronomy are low in popularity. In terms of attractions and activities in the area, assessment was based on two pillars: the input from questionnaires and the reviews from Trip Advisor. The most significant activities, in terms of popularity and quality of experience, concern local gastronomy and hiking (gorges crossing) while many other attractions and activities show low popularity and levels of experience. These results are confirmed by the reviews posted on Trip Advisor.

The overall assessment of tourism resources is very positive (Mean=4.1/5). More specific, hospitality, relationship with the locals, quality of catering and accommodation, Tranquility, safety and respect of privacy are the main strengths of the destination. However, infrastructure, local transport, accessibility and the quality of entertainment are pointed out as sections requiring improvement. A main weakness is identified as the low environmental awareness shown by the locals. A number of actions to correct this, are proposed by the respondents and include environmental awareness campaigns reducing the use of plastic (bags, glasses, straws), the provision of running drinking water instead of an overconsumption of plastic bottles, the separation and recycling of waste, the avoidance of throwing plastic items into the sea. Therefore, the overall grading of the area as an alternative tourism destination was scored at 7.3/10 ( $\mathrm{SD}=1,94)$, clearly indicating the alternative character but also the room for improvement. Findings show a remarkable profile of inbound tourism. The area attracts mainly visitors from Central and Western Europe, with middle or high income and higher education, who organize their trip on their own and stay for at least 2 weeks. The segmentation based on their special characteristics highlighted 
three clusters groups of equivalent weight: the "Eternal Lovers", the "Devoted Families" and the "Adventurers". All visitors are characterized by a high degree of satisfaction and loyalty to the venue, which is a very positive element for area's promotion. Moreover, the observed repeated visits in $70 \%$ of tourist flows combined with the relatively high age profile of visitors, may be a reason for shrinking incoming tourism in the future. Consequently, the "Adventurers", who represent $30 \%$ of the total, who visited the area for the first time and are younger, are the most dynamic and prominent cluster.

The choice of this alternative tourism destination instead of mass tourism is a conscious decision and is related to their strong interest in sustainability and in minimizing the negative impact of tourism development. The low performance of the area in relation to the environment is treated with similar interest and concern by respondents, resulting in the area being ranked as an alternative destination but with room for improvement. In this context, Juvan and Dolnicar point out that tourists can help to reduce negative environmental impacts "by making environmentally sustainable vacation and behaving in an environmentally sustainable manner while at the destination" (2016:30).

Apart from the need for relaxation and contact with nature, the interest of tourists in activities related to the environment, culture and the authentic local experience is substantial, while their perceived experience of such activities exceeds their expectations. Nevertheless, the commercial image of the area continues to focus on the "Sun - Sea - Sand" model and does not adequately promote complementary tourism resources, highlighting a gap between tourism supply and demand which should be addressed. In relation to the other characteristics of the area's tourism product, safety, hospitality, tranquillity, catering and accommodation are its strong points while weaknesses concern infrastructure, accessibility, transport, entertainment and mainly environmental awareness. Adopting the above results, the researchers formulated a proposal for the new model of tourism development of the area which includes the enrichment and upgrade of the existing tourism product into a multi-faceted product that will balance the alternative forms of tourism the area can offer with coastal tourism and the local agri-food sector supported by a sustainable development management pattern. The adoption and implementation of the proposed model leads to a pioneering combination of coastal, rural and alternative tourism and is estimated to be a vehicle for the transformation of the SW front of Chania Regional Unit from an occasional alternative tourism destination to a sustainable alternative destination model that protects its assets/resources i.e. nature, culture, customs, locality, gastronomy, longevity, safety, hospitality, and at the same time meeting the motivations and expectations of the "modern tourists". The new tourism product will combine the unique experience of health, tranquillity and relaxation offered by the natural environment and the beaches of the area, with the active holidays through alternative forms of tourism, thus creating a variety of options to visit and a product that is attractive all year round (while easing the load of the coastal zone). Regarding the management model of tourism development, which is a key factor for the successful implementation of the upgraded tourism product, a model based on the principles of sustainable development is proposed as formulated by the Global Sustainable Tourism Council (GSTC, 2019) in agreement with the SDGs. The management model splits into four axes related to management, society, economy, culture and environment. This planning approach is expected to create competitive advantage for the destination and lead to sustainable development (Grilli et al., 2021).

\section{CONCLUSION}

According to López-Sánchez and Pulido-Fernández "any competitive strategy for the positioning or repositioning of a destination should consider not only the supply-side perspective, but also the demand-side” (2017:262). The above analysis points out that in the process of comprehensive planning for tourism and sustainable regeneration of a destination the important elements are not only the investigating and analysis of the main characteristics of the tourists who visit each destination but also their views, expectations and experiences. The current tourists have more travel experiences, as people today travel more than any other period. Doubtless, they are more informed about destinations, cultures, tourism services etc., are becoming more conscious of the environment and often seek destinations which are certified as sustainable.

In addition, modern tourists are gradually involved into a movement that prioritizes local culture and community over mass tourism. In this context, the sustainable strategic planning methodology is proposed to be based not only on the analysis of tourism resources and supply but also on tourism demand. The evaluation of the destination's image through primary research and content processing from digital tourism platforms may produce significant knowledge for local planners. Based on this information, it is possible to assess the current tourism development as well as to examine the potential for enriching the tourism product and to adapt a sustainable management model accordingly (Figure 1).

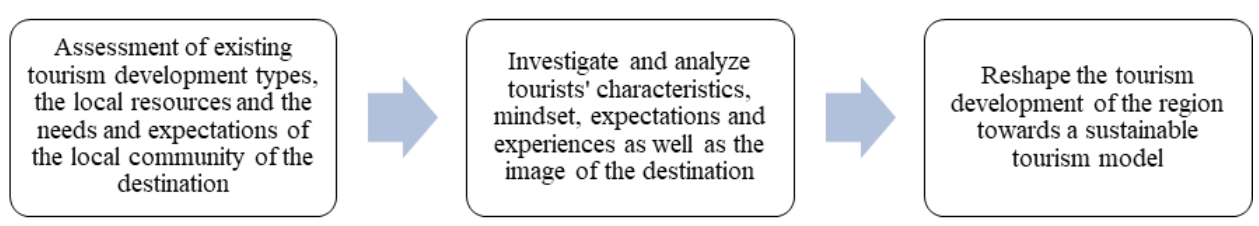

Figure 1. Strategic Planning Concept (Source: Own elaboration)

The researchers presented their proposal for sustainable rejuvenation to the municipal authority of the study area, in an effort to receive feedback, highlight the benefits and the challenges in its implementation. The local authorities consider that the biggest challenge would be the difficulty in changing the mentality of locals and especially those who are involved in tourism businesses as they do not share the need for change and continue to support a tourism model with weaknesses and low level of sustainability, which, in short term, continues to attract tourists and make a profit. The shock of the pandemic of Covid-19 could be a milestone fostering openness to change, with a new way of thinking and acting. 
The research results could constitute the basis to measure changes in tourists' behaviour of the specific destination especially after the pandemic covid-19 as well as to quantify the impact of future local improvement initiatives. In addition, as further research, the methodological approach depicted can be applied to other destinations with similar characteristics which also need a sustainable rejuvenation. Its results could be used for comparative evaluation.

\section{REFERENCES}

Artuger, S., \& Çetinsöz, B.C. (2017). The Impact of Destination Image and the Intention to Revisit: A Study Regarding Arab Tourists. European Scientific Journal. 13(5), 82-98. https://doi.org/10.19044/esj.2017.v13n5p82

Babbie, E. (2011). Introduction in Social Research, Athens: Kritiki.

Carvache-Franco, W., Carvache-Franco, M., Carvache-Franco, O., \& Hernández-Lara, A.B. (2020). Motivation and segmentation of the demand for coastal and marine destinations. Tourism Management Perspectives, 34, 100661. https://doi.org/10.1016/j.tmp.2020.100661

Chiu, W., Zeng, S., \& Cheng, P.S.T. (2016). The Influence of Destination Image and Tourist Satisfaction on Tourism loyalty: a case study of Chinese tourists in Korea International Journal of Culture, Tourism and Hospitality Research, 10 (2), 223-234.

Christou, E. (1999). Survey in the Touristic Market. Athens: Interbooks.

Cuenca, A.C., Canales, P., Bigné, E., Andreu, L., \& Ruiz, C. (2020). Analysis of the Tourist Destinations web Content through Landscapes. In J. Martí-Parreño, R. Gómez-Calvet, J. Muñoz de Prat (Eds.), Proceedings of the 3rd International Conference of Tourism Research, 17-26, UK: ACPI

Dolnicar, S. (2020). Designing for more environmentally friendly tourism. Annals of Tourism Research, 84, 102933. https://doi.org/10. 1016/j.annals.2020.102933

Fraiz, J.A., de Carlos, P., \& Araújo, N. (2020). Disclosing homogeneity within heterogeneity: A segmentation of Spanish active tourism based on motivational pull factors. Journal of Outdoor Recreation and Tourism, 30,100294. https://doi.org/10.1016/j.jort.2020.100294

Grilli, G., Tyllianakis, E., Luisetti, T., Ferrini, S., \& Turner, R.K. (2021). Prospective tourist preferences for sustainable tourism development in Small Island Developing States. Tourism Management, 82, 104178. https://doi.org/.1016/j.tourman.2020.104178.

Hall, M.C. (2019). Constructing sustainable tourism development: The 2030 agenda and the managerial ecology of sustainable tourism. Journal of Sustainable Tourism, 27:7, 1044-1060. https://doi.org/10.1080/09669582.2018.1560456

Juvan, E., \& Dolnicar, S. (2016). Measuring environmentally sustainable tourist behaviour. Annals of Tourism Research, 59, 30-44, https://doi.org/10.1016/j.annals.2016.03.006.

Kastenholz, E., Eusébio, C., \& Carneiro, M.J. (2018). Segmenting the rural tourist market by sustainable travel behaviour: Insights from village visitors in Portugal. Journal of Destination Marketing \& Management, 10, 132-142. https://doi.org/10.1016/j.jdmm.2018.09.001

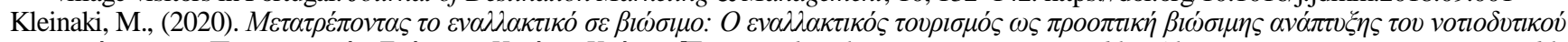

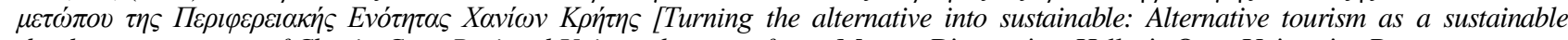
development prospect of Chania-Crete Regional Unit southwestern front., Masters Dissertation, Hellenic Open University, Patras

Kyriakaki, A., Stavrinoudis, T., \& Daskalopoulou, G. (2019). Investigating the key factors influencing the international tourists' decision-making on choosing a destination. In Katsoni, V. and Spyriadis, Th. (Eds), Cultural and Tourism Innovation in the Digital Era, Sixth International IACuDiT Conference, Athens, 2019. Springer, 335-352.

Kyriakaki, A., Stavrinoudis, T., Doumi, M., \& Riga, A. (2017). Factors influencing destination recommendation and tourists' revisit intentions. In Cebeci, K., Pawlicz, A., and Altaher, A. (Eds), MIRDEC-6th, International Academic Conference on Social Multidisciplinary, Economics, Business and Finance Studies, Sciences, Global Meeting of Social Science Community, Conference Proceedings, 27-29 November 2017, Lisbon, Portugal, 77-92, ISBN:978-605-82290-5-1

Kyriakaki, A., Stavrinoudis, T., Doumi, M., Proiou, E., \& Meni, D. (2016). Tourist satisfaction and destination loyalty. The case of Turkish visitors on the island of Chios. Proceedings of the 3rd International Cesme-Chios History, Culture and Tourism Symposium, 3 - 5 November, EgeUniveristy, Izmir - Turkey

López-Sánchez, Y., \& Pulido-Fernández, Y.I. (2016). In search of the pro-sustainable tourist: A segmentation based on the tourist "sustainable intelligence". Tourism Management Perspectives, 17, 59-71. https://doi.org/10.1016/j.tmp.2015.12.003

López-Sánchez, Y., \& Pulido-Fernández, Y.I. (2017). Factors influencing the willingness to pay for sustainable tourism: a case of mass tourism destinations, International Journal of Sustainable Development \& World Ecology, 24:3, 262-275. https://doi.org/ 10.1080/13504509.2016.1203372

Paulino, I., Lozano, S., \& Prats, L. (2021). Identifying tourism destinations from tourists' travel patterns. Journal of Destination Marketing \& Management, 19, 100508, ISSN 2212-571X. https://doi.org/10.1016/j.jdmm.2020.100508

Prince, S., \& Ioannides, D. (2016). Contextualizing the complexities of managing alternative tourism at the community-level: A case study of a Nordic eco-village. Tourism Management, 60, 348-356. https://doi.org/10.1016/j.tourman.2016.12.015

Rate, S., Moutinho, L., \& Ballantyne, R. (2018). The New Business Environment and Trends in Tourism. In L. Moutinho \& A.VargasSanchez (Eds.), Strategic Management in Tourism, 3rd Edition. 1-15, Boston, MA: CABI

Rizal, A., Apriliani, I.M., \& Permana, R. (2020). Sustainability Assessment of Coastal Development in southern region of West Java Province, Indonesia. GeoJournal of Tourism and Geosites, 30(2spl), 808-817. https://doi.org/10.30892/gtg.302spl05-50

Ruhanen, L. (2010). Where's the strategy in tourism strategic planning? Implications for sustainable tourism destination planning. Journal of Travel and Tourism Research, 10(1/2), 58-76.

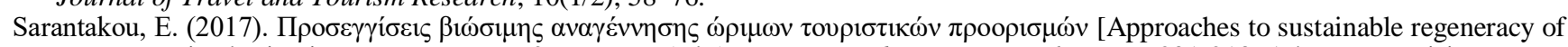
mature tourist destinations]. In P. Tsartas \& P. Lytras (eds.), Tourism and Tourism Development, 201-213, Athens, Papazisi.

Soulard, J., Knollenberg, W., Bynum Boley, C., Perdue, R.R., \& Gard McGehee, N. (2018). Social capital and destination strategic planning. Tourism Management, 69, 189-200. https://doi.org/10.1016/j.tourman.2018.06.011

Tsartas, P., Zouganeli, S., Trihas, N., Diamanti, E., and Samara, H. (2010) SIT Vs. 3S: The tourism identity of Greek destinations. In ATLAS Annual Conference "Mass Tourism VS Niche Tourism”. Limassol, CY

Veasna, S., Wu, W.Y., \& Huang, C.H. (2013). The impact of destination source credibility on destination satisfaction: The mediating effects of destination attachment and destination image. Tourism Management, 36, 511-526. https://doi.org/10.1016/j.tourman.2012.09.007

*** GSTC (2019). GSTC Destination Criteria Version 2.0. 2020, May 10. https://www.gstcouncil.org/gstc-criteria/gstc-destination-criteria/

*** Hellenic Statistical Authority (2019). Table 10- Arrivals at hotels and similar establishments (excluding tourist campsites), by Regional Unit and Municipality for 2018. https://www.statistics.gr/en/statistics/-/publication/STO12/2018 [Accessed the 18th of May 2020, 11.45]

*** UNWTO \& UNDP (2018). Tourism and the sustainable development goals - Journey to 2030. https://www.eunwto.org/doi/book/10.18111/9789284419401 